\title{
Impact Of Metacognitive Awareness On Performance Of Students In Chemistry
}

\author{
Fazal ur Rahman, Allama Iqbal Open University, Pakistan \\ Nabi Bux Jumani, Allama Iqbal Open University, Pakistan \\ Muhammad Ajmal Chaudry, Allama Iqbal Open University, Pakistan \\ Saeed ul Hasan Chisti, International Islamic University, Pakistan \\ Fahim Abbasi, International Islamic University, Pakistan
}

\begin{abstract}
The impact of metacognitive awareness on students' performance has been examined in the present study. 900 students of grade X participated in the study. Metacognitive awareness was measured using inventory, while performance of students was measured with the help of researcher made test in the subject of chemistry. Results indicated that metacognitive awareness was significantly correlated with the performance of students. The highly metacognitively aware science students performed well on the test. Results further indicated that there was no significant difference in the metacognitive awareness of male and female students.
\end{abstract}

Keywords: Metacognitive awareness; students' performance, Metacogntion, chemistry

\section{INTRODUCTION}

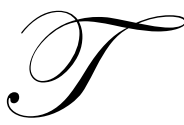

he Greek word meta signifies going beyond, so metacognition is cognition that goes beyond ordinary thinking. The term "meta" refers to second order knowledge. An early definition of metacognition by Flavell (1976) has become regularly quoted in the literature. He referred metacognition as "One's knowledge concerning one's own cognitive processes and products or anything related to them...Metacognition refers, among other things, to the active monitoring and consequent regulation and orchestration of theses processes in relation to the cognitive objects or data on which they bear..." (p. 232).Metacognition has a number of concrete and important effects on learning.

It plays an important role in oral comprehension, reading comprehension, problem solving, attention, memory, social cognition, personality development, communication and various types of self-control and selfinstruction which are key concerns for school (Flavell, 1987). Many researchers believe that metacognition holds great deal of promise for helping students do better. Metacognition has been linked to a wide variety of positive academic outcomes for students such as better grades and performance on tests of intelligence.

Past researches have revealed a close relationship between metacognition and performance. It is reasonable to suppose that optimizing the use of metacognitive behavior can be addressed in terms of: 1) the appropriate use of a relevant metacognitive function, 2) the optimal frequency of metacognitive actions relevant cognitive actions, and 3 ) the optimal sequencing of metacognitive actions and functions (Wilson \& Clark, 2002)

There is no doubt that students are using metacognition, but regardless of how many metacognitive acts are used, success is not guaranteed. Metacognition becomes essential when tasks are more challenging.

Maqsud (1997) investigated the effects of metacognitive skills and nonverbal ability on academic achievement of high school pupils. He found that metacognitive ability tends to associate positively with academic attainment of high school pupils. 
Everson; Tobias \& Laitusis (1997) examined the correlation among measures of metacognitive knowledge, learning and study strategies, and academic achievement across the domains of verbal ability and mathematics. They found that metacognitive knowledge was generalizable across both the verbal and mathematical domains. A positive correlation was also found between the two knowledge-monitoring measures and students' confidence estimates. Similarly Tobias; Everson; \& Laitusis (1999) also found that knowledge monitoring had a significant relationship with school grades, continue to indicate that accurate monitoring is an important variable in school learning.

Chisholm (1999) cited that Wang (1993) examined cultural-familial predictors of children's metacognitive and academic performance with a sample of Caucasian, Hispanic and African-American children in second grade. Findings indicated that although the Caucasian and Hispanic students had higher mean scores than the AfricanAmerica students, the difference was due to the students' socio-economic status and not their ethnicity.

Phakiti (2003) investigated the relationship of cognitive and metacognitive strategy used to EFL reading achievement test performance and found that a) the use of cognitive and metacognitive strategies had a positive relationship to the reading test performance; and b) highly successful test takers reported significantly higher metacognitive strategy use than the moderately successful ones who in turn reported higher use of these strategies than the unsuccessful test takers.

Rysz (2004) while identifying metacognitive thoughts adult students had while learning elementary probability and statistics concepts found that students can earn above average grades using limited or no metacognitive awareness, but those who provided evidence of cognitive awareness and self monitoring were better able to report an understanding of probability and statistics concepts. Also Bigozzi \& Vezzani (2005) investigated the effects of individual writing on metacognitive awareness concerning scientific concepts. They found that individual writing enhances the use of metacognitive terms and the frequency of use regarding terms, which distinguish appearance from reality. Further Mason \& Nadalon (2005) found that overall students' metacognitive competence significantly correlated with their achievement in subjects. Similarly, Coutinho (2006) concluded that students with good metacognition tend to be successful students. Students with poor metacognition tend to perform poorly.

In sum, it may be concluded that there is a positive correlation between metacognition and academic success. Metacognition is an awareness and understanding of how one thinks and uses strategies during reading and writing.

\section{OBJECTIVES OF THE STUDY}

The objectives of the study were to:

- $\quad$ Measure metacognition of the science students.

- Determine the impact of metacognitive awareness on performance of student's in chemistry.

\section{RESEARCH HYPOTHESES}

There is a significant correlation between Metacognitive awareness and performance of students on the test.

$\mathbf{H}_{\mathbf{0}}: \quad$ There is no significant correlation between Metacognitive awareness and performance of students.

\section{METHODOLOGY OF THE STUDY}

This was a correlation study. Metacognitive awareness of students was assessed using metacognitive inventory. While students' performance was measured by using researcher made test in the subject of Chemistry. 


\section{INSTRUMENTS OF THE STUDY}

\section{Metacognitive Inventory}

After an extensive literature review the researcher adapted Schraw and Dennison, 1994 Inventory because it is a reliable and valid instrument available. Internal consistency of the inventory was excellent, ranging from 0.93 to 0.88 , thus provided a reliable assessment of metacognitive awareness (Schraw \& Dennison, 1994). The inventory represents two component categories of metacognition, knowledge of cognition and regulation of cognition. The inventory consisted of 52 items. The inventory based on five point Likert scale ranging from "Always" to "Not at all" in which the participants were asked to tick appropriate box.

\section{Achievement Test}

The researcher developed an achievement test in the subject of chemistry. The test was not memory based but it involved deep thinking and metacognitive skills used by the learners in their learning. Test items were based on secondary school curriculum of chemistry for grade (IX) textbook board. Three indicators were kept in mind while constructing items i.e. the difficulty, understandability and relevance of items to the objectives of the study. The initial form of the test consisted of 68 multiple choice items. Thus with the help of advisor and experts, the researcher reviewed statements to find out how well the respondents understood the items being asked. Discussion resulted in the removal and modification of a number of items from the test. The final draft of the test consisted of 30 items.

\section{Administration of Instruments}

Before giving instruments, a brief introduction about the research was provided to the students. The students were asked to read the statements carefully and indicate their response by tick marking the appropriate box. They were told that there are no right and wrong answers to the statement in the inventory. They were further asked to rate themselves on use of metacognition while learning as accurately and honestly as they could. The inventory was first administered to the respondents followed by the subject-based test. Average completion time for the inventory and achievement test was ten and thirty minutes respectively.

\section{SAMPLE OF THE STUDY}

The sample size was determined by using criteria given by Johnson \& Christensen (2000.p178). For this study a sample of 525 male students and 375 female students of grade $\mathrm{X}$ were selected randomly from the population.

\section{ANALYSIS OF DATA} tables:

The data were analyzed using SPSS 13. A summary of the data analysis is presented in the following

Table 1: Group Statistics of Male and Female Students

\begin{tabular}{|llcccc|}
\hline Gender & & N & Mean & Std. Deviation & Std. Error Mean \\
\hline Test score & Male & 525 & 20.9 & 4.7 & .20 \\
Student's MAI & Female & 375 & 20.0 & 4.4 & .23 \\
& Male & 525 & 150.2 & 10.6 & .46 \\
& Female & 375 & 149.9 & 14.6 & .76 \\
\hline
\end{tabular}

The above table reveals that male students have a high mean score at both the test and metacognitive inventory. 
Table 2: Correlations between MAI And Test Score of all Students $(\mathrm{N}=900)$

\begin{tabular}{|c|c|c|c|}
\hline & & Student's MAI & Test score \\
\hline Student's MAI & Pearson Correlation & 1 & $.45(* *)$ \\
\hline Test score & Pearson Correlation & $.45(* *)$ & 1 \\
\hline
\end{tabular}

The table also indicates a positive relationship $(r=0.45)$ between MAI and test score of students.

\section{TESTING OF RESEARCH HYPOTHESIS}

There is a significant correlation between Metacognitive awareness and performance of students on the test.

Table 3: ANOVA Table

\begin{tabular}{|lllclccc|}
\hline & & & Sum of Squares & df & Mean Square & F & Sig. \\
\hline & Between Groups & (Combined) & 5328.5 & 58 & 91.8 & 5.8 & .00 \\
\cline { 2 - 8 } Test score * Student's MAI & Within Groups & 13259.9 & 841 & 15.8 & & \\
\cline { 2 - 9 } & Total & 18588.4 & 899 & & \\
\end{tabular}

Table 3 reveals a significant correlation between metacognitive awareness and performance of students on the test. It further indicates that highly metacognitively aware students were more likely to perform better on the test.

\section{FINDINGS OF THE STUDY}

- $\quad$ The overall mean score of male students on the test and MAI was greater than female students.

- There was significant correlation between metacognitive awareness and performance of the students on the test.

- $\quad$ The results of regression analysis indicated that Student's MAI was significantly accounted for difference in test score of students.

\section{RECOMMENDATIONS}

- $\quad$ Proper metacognitive strategies may be used by the science teachers as it has significant impact on students' performance. Further, students may be encouraged to use metacognitive strategies as it has significantly correlated with students' performance.

- This was a co relational study based on quantitative data. The study was delimited to secondary school science students and subject of chemistry, therefore a study may be conducted on other subjects and level.

- $\quad$ There is a need for exploring relationship of cause and effect between metacognition and academic performance.

- Qualitative Research is also needed to examine age related factors and other psychological factors affecting metacognition.

\section{DISCUSSION}

Results of the present study have important implication for education. However, it is worthwhile to mention that the findings of the present study based on quantitative data and correlation tests. An interesting direction for future research may be to undertake cause and effect relationship between metacognition and students performance. The results of the study indicated that there is no significant difference between metacognition of 
male and female science students. Thus the present study did not find any significant gender differences in metacognitive awareness. The results also provided a mean of support to previous researches on relationship of metacognition and academic achievement. The results of the study indicated that metacognition might play an important role in academic achievement of the students. The statistical analysis indicated that highly metacognitively aware students performed better on the test than low metacognitively aware students. Thus it is in line with the findings of the previous researches.

This study also has some limitations, which may require attention in future research. Firstly, the sample of the present study consisted of science students of class X. So the inventory may be applied to all students of different subjects at different level. Secondly, the criterion of students' performance was the researcher made test in the subject of chemistry. However, this may not be a true indicator of students' performance. Therefore, different criteria for students' performance may used.

\section{AUTHOR INFORMATION}

Fazal ur Rahman works as a lecturer in the Department of Early childhood \& Elementary Teacher Education at Allama Iqbal Open University, Islamabad fazalaiou@yahoo.com.

Dr. Nabi Bux Jumani works as a assistant professor in the Department Of Secondary Teacher Education at Allama Iqbal Open University, Islamabad.nbjumani@yahoo.com.

Dr. Muhammad Ajmal Chaudry works as a lecturer in the Department Of Distance, Non Formal \& Continue Education at Allama Iqbal Open University, Islamabad.drajmal@yahoo.com.

Dr. Saeed ul Hasan Chisti works as a Director, at Institute Of Professional Development, International Islamic University, Islamabad. Saeed-ul-hasan@ hotmail.com.

Fahim Abbasi is $\mathrm{PhD}$ scholar at Department Of Education, International Islamic University, Islamabad. Abbasi.fahim@gmail.com.

\section{REFERENCES}

1. Bigozzi, L \& Vezzani, C. (2005). Role Of Individual Writing on Metacognitive Awareness in Scientific Concepts Learning. A study conducted by the Department of Psychology, University of Florence. Italy.

2. Chisholm, J. M. (1999). The Effects of Metacognition, Critical Thinking, Gender, and Gender Role Identification on Academic Achievement in The Middle Years. A master degree thesis, Mount Saint Vincent University. Hailfax, Nova Scotia.

3. Coutinho, S. A. (2006). A Model of Metacognition, Achievement Goal Orientation, Learning Style and Self Efficacy. An unpublished PhD thesis. Department of Psychology, Northern Illinois University. Illinois.

4. Everson, H. T; Tobias, S; \& Laitusis, V. (1997). Do Metacognitive Skills and Learning Strategies Transfer Across Domains? Paper presented at a Symposium On Assessing Metacognitive Knowledge Monitoring held at the annual convention of the American Educational Research Association, Chicago, March 1997.

5. Flavell, J. H. (1976). Metacognitive Aspects of Problem Solving. In L.B. Resnick (Eds). The Nature of Intelligence. New York: Erlbaum.

6. Flavell, J. H. (1987). Speculations about the Nature and Development of Metacogniton. In F. Weinert, \& R. Kluwe, (Eds) Metacogniton, Motivation and Understanding. Hillsdale, NY: Erlbaum. Pp.21-29.

7. Johnson, B \& Chistensen, L. (2000). Educational Research: Quantitative and Qualitative Approaches. Needam Heights, MA: Allyn \& Bacon.

8. Maqsud, M. (1997). Effects of Metacognitive Skills and Nonverbal Ability on Academic Achievement of High School Pupils. Educational psychology, 17(4), 387-397.

9. Mason, L \& Nadalon, C. (2005). Measuring High School Students' Metacognitive Knowledge,skills and Attitude through AILI Relationship With Gender, Grade, Curriculum And Achivement. Study conducted at University of Padua, Italy. 
10. Phakiti, A. (2003). A Closer Look at the Relationship of Cognitive and Metacognitive Strategy Used To EFL Reading Achievement Test Performance. Language Testing, 20, 26-54.

11. Rysz, T. (2004). Metacognition in Learning Elementary Probability and Statistics. An unpublished EdD thesis. University of Cincinnati. USA.

12. Schraw, G; \& Dennison, R. (1994). Assessing Metacognitive Awareness. Contemporary Educational Psychology. 19(4)(pp460-475).

13. Wilson, J; \& Clarke, D. (2002). Monitoring Mathematical Metacognition. A paper presented at the annual meeting of the American Educational Research Association, New Orleans, LA, April 1-5, 2002. 